\title{
DONDE LA POLÍTICA NO ALCANZA. EL RETO DE DIPLOMÁTICOS, CÓNSULES Y AGENTES CULTURALES EN LA RENOVACIÓN DE LAS RELACIONES ENTRE ESPAÑA Y AMÉRICA, 1880-1939
}

\author{
Pilar Cagiao Vila (ED.)
}

Madrid, España/Frankfurt, Alemania, 2018, Iberoamericana-Vervuert, 285 páginas ISBN: 978-84-16922-92-5

La obra editada por Pilar Cagiao Vila, titulada Donde la política no alcanza. El reto de diplomáticos, cónsules y agentes culturales en la renovación de las relaciones entre España y América, 1880 1939, ofrece un interesante y novedoso compendio de siete capítulos -además de una introducción de la misma Cagiao Vila- cuyo tema central de análisis es la actuación de diplomáticos, cónsules, y, más en general, de los agentes culturales que, con sus acciones, conectaron España y América.

En el ámbito de las publicaciones sobre las relaciones diplomáticas y culturales, la obra destaca por la enriquecedora propuesta que aporta al debate sobre los actores individuales como sujeto principal del devenir histórico, enfocando el interés en los intercambios, formales e informales, entre las dos orillas del Océano, protagonizados por los agentes culturales y diplomáticos.

El origen de los artículos reunidos en esta obra es el proyecto de investigación homónimo dirigido por Pilar Cagiao Vila y protagonizado por los/las autores/as. Como señala Cagiao Vila en su excelente introducción, la tesis planteada a lo largo de la obra es que la actuación individual de los actores investigados constituye un entramado sobre el que se construyen redes y vínculos colectivos de tipo económico, cultural y diplomático. En este sentido, la originalidad de la obra reside en individuar el papel que cada uno desarrolló a partir de las experiencias personales, y señalar cómo, tejiendo vínculos, estos mismos llegaron por fin a ser un elemento fundamental de las políticas estatales (de manera implícita o explícita) y de las relaciones entre Estados.

Los primeros cuatro autores (Cagiao Vila, Sánchez Andrés, Martínez Riaza, Vélez Jiménez) se interesan por la actuación de los actores "formales" en el seno de las representaciones diplomáticas. De ellos, Pilar Cagiao Vila (Universidad de Santiago de Compostela) trata del singular caso de "Matías Alonso Criado o la diplomacia trasnacional". La autora aborda la trayectoria personal y profesional de Matías Alonso Criado que, español 
de nacimiento, en diferentes momentos actuó como representante de España en Uruguay, del Paraguay en Madrid, de Paraguay y Chile en Uruguay, y delegado de Ecuador en España. Se enfatiza la actuación de Alonso Criado que, a pesar de no ser originalmente diplomático de profesión, fue un agente de la diplomacia cultural, promotor de diversas actividades, actividad cuyo origen se encuentra en su red de relaciones personales.

Algunas similitudes presenta el caso tratado en el segundo capítulo por Agustín Sánchez Andrés (Universidad Michoacana de San Nicolás de Hidalgo) "Entre la literatura y la diplomacia. La gestión de Vicente Riva Palacio en Madrid, 1886 - 1896”. En este caso también, un particular interés revisten las relaciones personales del literato, político, militar y jurista Vicente Riva Palacio, que llegó a representar al Gobierno de Porfirio Díaz en España y contribuyó a la normalización de las relaciones entre los dos países. Sobre todo, Riva Palacio fue un agente diplomático en pleno sentido, actuando en diferentes ámbitos, sea ya contribuyendo a difundir una imagen positiva del régimen mexicano en España, ya mostrando la convergencia de intereses de los dos países en el Caribe, y, particularmente, destacando en las celebraciones del IV Centenario, en 1892.

Siguiendo el orden de los trabajos, el estudio de Ascensión Martínez Riaza (Universidad Complutense de Madrid) "Agentes culturales y hombres prácticos. Clemente Palma y José Gálvez Barrenechea en el consulado del Perú en Barcelona (1900 - 1919)” nos habla del papel clave de agentes culturales que desarrollaron dos cónsules. La autora se centra en estudiar el actuar "práctico" de Clemente Palma y José Gálvez Barrenechea, escritores y cónsules peruanos en Barcelona, en sus labores de atención a la propaganda, los comercios, las líneas de navegación y los conciudadanos. En ambos casos, se destaca cómo estudiar su actuación nos abre una ventana sobre la visión que tenían de la sociedad española y catalana de la época.

Sigue el trabajo de Palmira Vélez Jiménez (Universidad de Zaragoza), "Hacer patria en Hispanoamérica. El Instituto Diplomático y Consular”, que ofrece un interesante análisis sobre la formación de los diplomáticos españoles que ejercían en el exterior, entre 1911 y 1931. A través del examen de la instrucción impartida en el Instituto Libre de Enseñanza de las Carreras Diplomáticas y Consular y Centro de Estudios Marroquíes, sus programas, temarios, profesores y alumnos, la autora nos desvela las herramientas aportadas a los futuros diplomáticos, de cara a sus trabajos futuros.

Los tres trabajos que siguen exponen la diplomacia ejercida por varios individuos, como empresarios o agentes comerciales, aunados por no trabajar en el servicio exterior de las legaciones y consulados 
El primero es el trabajo póstumo de Gabriela Dalla-Corte Caballero (Universidad de Barcelona) "Federico Rahola y la revista Mercurio: diplomacia consular iberoamericana entre la Guerra de Cuba y la primera Guerra Mundial”, en el que la autora nos ayuda a situar la revista, y a su director, como agentes económicos y comerciales, y como voces de primera importancia en auspiciar, durante las primeras dos décadas del siglo XX, nuevas relaciones económicas, culturales y comerciales entre América y Cataluña.

El trabajo de Rosario Márquez Macías (Universidad de Huelva) "Carolina Marcial Dorado (1889-1941): embajadora de lo hispano en Estados Unidos. El Bureau de Información proEspaña” nos acerca a la única mujer del grupo de agentes culturales aquí presentados. Mediante el estudio de la trayectoria de la directora del bureau, se puede apreciar cómo la institución que ella dirigía actuó para promover en los Estados Unidos la imagen de una España moderna y potencial socio económico-comercial. Se revela además la tentativa de crear una red intelectual iberoamericana.

Finalmente, se presenta el trabajo de Manuel Andrés García (Universidad de Huelva) "A la sombra del Doce de Octubre: la gloria anhelada y fugaz de José María González García, 'Columbia"'. El capítulo presenta la actuación en sentido hispanoamericanista del periodista asturiano, destacando por un lado su aporte a las relaciones intelectuales y culturales entre los países hispanohablantes, y por otro, fundamentalmente, tratando de sus labores con la prensa del periodo para impulsar las celebraciones del Doce de Octubre.

En suma, no podemos dejar de señalar la importante contribución de los/las autores/as a esta obra, y la cuidadosa edición de Pilar Cagiao Vila. A partir del estudio de los actores de la diplomacia se ha podido desentrañar el entramado de redes, relaciones, intercambios culturales, económicos, comerciales e intelectuales del periodo. Desde luego, este libro constituye un excelente aporte a la historia de las relaciones entre América y España.

\section{Chiara Pagnotta}

Universidad de Cádiz 